\title{
Impact of the effect of economic crisis and the targeted motorcycle safety programme on motorcycle-related accidents, injuries and fatalities in Malaysia
}

\begin{abstract}
In 1997, a Motorcycle Safety Programme (MSP) was introduced to address the motorcyclerelated accident problem. The MSP was specifically targeted at motorcyclists. In addition to the MSP, the recent economic recession has significantly contributed to a reduction of trafficrelated incidents. This paper examines the effects of the recent economic crisis and the MSP on motorcycle-related accidents, casualties and fatalities in Malaysia. The autocorrelation integrated moving average model with transfer function was used to evaluate the overall effects of the interventions. The variables used in developing the model were gross domestic product and MSPs. The analysis found a $25 \%$ reduction in the number of motorcycle-related accidents, a $27 \%$ reduction in motorcycle casualties and a $38 \%$ reduction in motorcycle fatalities after the implementation of MSP. Findings indicate that the MSP has been one of the effective measures in reducing motorcycle safety problems in Malaysia. Apart from that, the performance of the country's economy was also found to be significant in explaining the number of motorcycle-related accidents, casualties and fatalities in Malaysia.
\end{abstract}

Keyword: Motorcycle safety programme; Gross domestic product; Autocorrelation integrated moving average model; Transfer function model 